\title{
Anterior uveitis following eyebrow epilation with alexandrite laser
}

This article was published in the following Dove Press journal:

International Medical Case Reports Journal

7 September 2015

Number of times this article has been viewed

\author{
Yunus Karabela' \\ Mustafa Eliaçık² \\ 'Department of Ophthalmology, \\ Esenler Hospital, Istanbul Medipol \\ University, Istanbul, Turkey; \\ ${ }^{2}$ Department of Ophthalmology, \\ Kadıköy Medipol Hospital, Istanbul \\ Medipol University, Istanbul, Turkey
}

Correspondence: Yunus Karabela Department of Ophthalmology, Esenler Hospital, Istanbul Medipol University, Birlik Mah, Bahçeler Cad, number 5, Esenler 34230, Istanbul, Turkey

Tel +90212440 1000

Fax +902124401010

Emailmrsbela@yahoo.com

\begin{abstract}
Ocular tissues are known to be sensitive to damage from exposure to laser emissions. This study reports the case of a female patient with acute unilateral anterior uveitis caused by alexandrite laser-assisted hair removal of the eyebrows. We report a 38 -year-old female who presented with unilateral eye pain, redness, and photophobia after receiving alexandrite $(755 \mathrm{~nm})$ laser epilation of both eyebrows. Best corrected visual acuity was 20/20 in both eyes. Right eye examination was normal. Left eye examination showed conjunctival injection and $2+/ 3+$ cells in the anterior chamber. Intraocular pressure and fundus examination were normal. Topical steroids and cycloplegic drops were prescribed for 3 weeks. At the end of the 3-week follow-up, best corrected visual acuity was 20/20, and intraocular pressure and fundus examination were normal in both eyes. The left eye was white, and the anterior chamber was clear. The patient continues to be monitored. In conclusion, without adequate protective eyewear, laser hair removal of the eyebrows with alexandrite laser can lead to ocular damage.
\end{abstract}

Keywords: uveitis, laser exposure, photothermolysis, laser hair removal, photoepilation

\section{Introduction}

Laser (or light) hair removal, also known as photoepilation, is one of the most commonly used laser- or light-based cosmetic medical procedures. ${ }^{1,2}$ In the literature, various cases of ocular complications have been reported following laser hair removal of the eyebrows, both with and without protective eyewear. ${ }^{3-13}$ This report describes the case of a female patient with acute anterior uveitis caused by alexandrite laser-assisted hair removal of the eyebrows while not wearing protective eyewear. This study and the methods of the case report were performed as per the tenets of the Declaration of Helsinki.

\section{Case report}

A 38-year-old female with mild myopic astigmatism and no history of ocular problems - specifically, no history of uveitis - underwent alexandrite laser-assisted hair removal of both eyebrows. Approximately 4-6 hours post-procedure, the patient began to experience pain, redness, and photophobia in the left eye. The next day, she presented at our clinic with the same complaints. Upon ophthalmic evaluation, best corrected visual acuity was 20/20 in both eyes. Examination of the right eye was normal. There was moderate ciliary injection and $2+/ 3+$ cells in the anterior chamber of the left eye. Intraocular pressure, vitreous, and retina examination were normal in the left eye. The patient reported that she had closed her eyes and covered them with her fingers during the laser hair removal procedure. She did not use protective eyewear. 
Topical prednisolone acetate 1\% (Pred Forte ${ }^{\circledR}$; Allergan, Inc., Istanbul, Turkey; eight times per day) and cyclopentolate hydrochloride 1\% (Sikloplejin; Abdi Ibrahim, Istanbul, Turkey; three times per day) eye drops were prescribed. Three days after the initiation of topical treatment, there was a reduction in anterior chamber cells to $1+/ 2+$ and conjunctival injection. Topical prednisolone eye drops were tapered to five times per day, and cyclopentolate hydrochloride was tapered to two times per day. Two weeks later, the left eye was white, and the anterior chamber was clear. Topical medications were gradually reduced and then discontinued. At the end of the 3-week follow-up, best corrected visual acuity was 20/20 in both eyes; slit-lamp biomicroscopy, intraocular pressure, and fundus examination of the left eye remained normal. At approximately 1 year post-procedure, the patient continues to be monitored by our clinic.

\section{Discussion}

Several types of lasers and light sources have been effective for unwanted body and facial hair reduction, including red spectrum ruby (694 nm), near-infrared red spectrum alexandrite laser (755 nm), diode laser (800 nm), neodymium-doped yttrium aluminum garnet laser (1,064 nm), and intense pulsed light (590-1,200 nm). These lasers work on the principle of selective photothermolysis, with the melanin in the hair follicles acting as the chromophore. The red and near-infrared wavelengths of the lasers penetrate the dermis, where they are absorbed by melanin in hair follicles. ${ }^{1-4}$ With a wavelength of $755 \mathrm{~nm}$, the alexandrite laser system is well absorbed by follicular melanin. The amount of energy absorbed depends on interference from other melanin-containing structures. In the anterior segment of the eye, the iris and ciliary body are tissues composed of melanin, which could be damaged from laser exposure during photoepilation. Thermal damage from alexandrite laser can occur to a depth of several millimeters, depending on user settings and skin type. ${ }^{3,5-13}$ Alexandrite laser using an average fluency of $15-20 \mathrm{~J} / \mathrm{cm}^{2}\left(7-50 \mathrm{~J} / \mathrm{cm}^{2}\right)$, with a $10 \mathrm{~mm}$ spot size $(10-15 \mathrm{~mm})$, at either a 5,10 , or $20 \mathrm{~ms}$ (range: 5-300 ms) pulse duration., ${ }^{2,14}$

As a result of Bell's phenomenon, elevation of the globe with lid closure during photoepilation causes absorption of laser energy and subsequent damage, with inflammation and pigment dispersion. The thin skin of the eyelids fails to prevent the penetration of laser beams into the eye; thus, ocular damage can occur., $4,5,8,10-12$

In the literature, many adverse effects following laser hair removal procedures have been reported, such as anterior uveitis, pupillary distortion, posterior synechiae, iris atrophy, nuclear cataract, visual field defect, macular hole, and retinal scarring. ${ }^{3-13}$

Elkin et $\mathrm{al}^{8}$ reported a 41-year-old male with bilateral iritis and iris atrophy without posterior synechiae. Lin et $\mathrm{al}^{9}$ described patients with pigment dispersion and temporary elevated intraocular pressure. Yalçındağ and Uzun ${ }^{10}$ reported a 36-year-old female who presented with unilateral anterior uveitis with posterior synechiae. Carrim et $\mathrm{al}^{11}$ reported a case of iris damage, acute anterior uveitis, and acute pigment dispersion with secondary increased intraocular pressure following use of alexandrite laser for photoepilation of the eyebrows. Parver et al ${ }^{12}$ described six cases of ocular injury directly related to laser hair removal/reduction procedures for the eyebrow, both with and without protective eye devices. In each case, the associated iris damage was permanent, and topical steroids were needed to address the associated uveitis. In one case, there was steroid-induced glaucoma that abated, but in another case, there was progression from ocular hypertension to uncontrolled glaucoma that required invasive intervention. In two cases, there was lens damage, leading to cataract surgery. Anaya-Alaminos et $\mathrm{al}^{13}$ described a case of retinal injury (foveal photocoagulation) directly related to an alexandrite laser hair removal procedure.

There are different factors that affect the safety of laser hair removal around the eyes: laser irradiance, exposure duration, spot size, and safety eyewear. ${ }^{1,2,14}$ It is understood from previously published laser user guides and reports that whether the laser parameters are changed or not, inadequate shielding will increase the risk of external and internal eye tissue damage.

In this case, though epilation was done for both the eyebrows, only one eye was affected. This may be due to the differences in the laser parameters applied, or the displacement of the laser probe or misdirection of the laser beam toward the eye. The last one is one of the most possible failures caused because of the practitioners. Unfortunately, which alexandrite laser hair removal parameters were used in this case is unknown.

\section{Conclusion}

This report describes a new case of anterior uveitis caused by alexandrite laser-assisted hair removal of eyebrows while not wearing protective eyewear. This method should not be suggested as a simple procedure, and individuals should be informed of the rare but potentially serious side effects. Furthermore, use of protective devices such as metal goggles should be mandatory during laser hair removal of the eyebrows. 


\section{Acknowledgments}

Written informed consent was obtained from the patient for publication of this case report. The authors advise that the Istanbul Medipol University Ethics Committee does not require ethical approvals for case reports.

\section{Author contributions}

All authors contributed toward patient treatment, data analysis, drafting and critically revising the paper, gave final approval of the version to be published, and agree to be accountable for all aspects of the work.

\section{Disclosure}

The authors report no conflicts of interest in this work.

\section{References}

1. Zandi S, Lui H. Long-term removal of unwanted hair using light. Dermatol Clin. 2013;31(1):179-191.

2. Liew SH. Laser hair removal: guidelines for management. Am J Clin Dermatol. 2002;3(2):107-115.

3. Le Jeune M, Autié M, Monnet D, Brézin AP. Ocular complications after laser epilation of eyebrows. Eur J Dermatol. 2007;17(6):553-554.

4. Sheikh A, Hodge W, Coupland S. Diode laser-induced uveitis and visual field defect. Ophthal Plast Reconstr Surg. 2007;23(4):321-323.
5. Herbold TM, Busse H, Uhlig CE. Bilateral cataract and corectopia after laser eyebrow epilation. Ophthalmology. 2005;112(9):1634-1635.

6. Shulman S, Bichler I. Ocular complications of laser-assisted eyebrow epilation. Eye (Lond). 2009;23(4):982-983.

7. Halkiadakis I, Skouriotis S, Stefanaki C, et al. Iris atrophy and posterior synechiae as a complication of eyebrow laser epilation. $J$ Am Acad Dermatol. 2007;57(2):S4-S5.

8. Elkin Z, Ranka MP, Kim ET, Kahanowicz R, Whitmore WG. Iritis and iris atrophy after eyebrow epilation with alexandrite laser. Clin Ophthalmol. 2011;5:1733-1735.

9. Lin CC, Tseng PC, Chen CC, Woung LC, Liou SW. Iritis and pupillary distortion after periorbital cosmetic alexandrite laser. Graefes Arch Clin Exp Ophthalmol. 2011;249(5):783-785.

10. Yalçındağ FN, Uzun A. Anterior uveitis associated with laser epilation of eyebrows. J Ophthalmic Inflamm Infect. 2013;3(1):45.

11. Carrim ZI, Chohan AW, Devlin HC. Iris damage and acute pigment dispersion following photoepilation. Eye (Lond). 2006;20(12): 1486-1488.

12. Parver DL, Dreher RJ, Kohanim S, et al. Ocular injury after laser hair reduction treatment to the eyebrow. Arch Ophthalmol. 2012;130(10): $1330-1334$

13. Anaya-Alaminos R, Muñoz-Ávila JI, González-Gallardo MC, Mora-Horna ER, García-Serrano JL, Ramírez-Garrido MV. Accidental foveal photocoagulation secondary to alexandrite laser. Eur $J$ Ophthalmol. 2014;24(5):808-810.

14. Nanni CA, Alster TS. Long-pulsed alexandrite laser-assisted hair removal at 5, 10, and 20 millisecond pulse durations. Lasers Surg Med. 1999;24(5):332-337.
International Medical Case Reports Journal

\section{Publish your work in this journal}

The International Medical Case Reports Journal is an international, peer-reviewed open-access journal publishing original case reports from all medical specialties. Previously unpublished medical posters are also accepted relating to any area of clinical or preclinical science. Submissions should not normally exceed 2,000 words or

\section{Dovepress}

4 published pages including figures, diagrams and references. The manuscript management system is completely online and includes a very quick and fair peer-review system, which is all easy to use. Visit http://www.dovepress.com/testimonials.php to read real quotes from published authors. 